\title{
Barton Fracture of the Distal Radius in Pregnancy and Lactation-Associated Osteoporosis: A Case Report and Literature Review
}

This article was published in the following Dove Press journal:

International Journal of General Medicine

\section{Gang Wang (D) \\ Xiaodong Bai $(\mathbb{D}$}

Department of Orthopedics, Beijing Friendship Hospital, Capital Medical University, Beijing 100050, People's Republic of China
Correspondence: Xiaodong Bai

Department of Orthopedics, Beijing Friendship Hospital, Capital Medical

University, Beijing I00050, People's

Republic of China

Tel +86-|0-63138753

Fax +86-10-63138353

Email orthopedics_bxd@163.com
Objective: Pregnancy and lactation-associated osteoporosis (PLO) is very rare, which typically occurs during the third trimester or during lactation. Many cases of PLO are associated with vertebral compression fractures or hip fractures, while distal radius fractures in patients with PLO are rarely reported.

Case Report: A 36-year-old patient presented with Barton fracture at 37 weeks of gestation. Temporary closed reduction and plaster external fixation were performed in emergency room. At 38 weeks of gestation, she gave birth to a healthy boy and began breastfeeding after delivery. Three days after delivery, the patient was admitted to the orthopedic ward for surgery and was diagnosed as PLO. The patient underwent open reduction and internal fixation and treated with weaning and supplementation of calcium carbonate and vitamin D. During the 1-year follow-up period, the results of laboratory tests and bone mineral density gradually returned to normal.

Conclusion: Clinicians should be alert to the possibility of PLO to avoid missed diagnosis. Accurate diagnosis and individualized treatment are of great significance for relieving pain and functional recovery of patients.

Keywords: pregnancy and lactation-associated osteoporosis, PLO, Barton fracture, bone mineral density, BMD, calcium, vitamin D, dual-energy X-ray absorptiometry, DEXA

\section{Introduction}

Pregnancy and lactation-associated osteoporosis (PLO) characterized by a transient but significant reduction in bone mineral density is a special form of osteoporosis, ${ }^{1}$ which typically occur during the third trimester or during lactation. ${ }^{2}$ Related symptoms include severe back or hip pain secondary to vertebral fractures and/or transient osteoporosis of the hip. ${ }^{3}$ Many cases of PLO associated with vertebral compression fractures or hip fractures have been reported. ${ }^{4-6}$ In contrast, distal radius fractures in patients with PLO are rarely reported. We report here a 36-yearold patient who presented with Barton fracture of the distal radius after suffering from minor trauma at 37 weeks of gestation.

\section{Case Report}

A 36-year-old woman, whose first child was a 6-year-old boy, was pregnant again. At 37 weeks of gestation, she accidentally fell while walking from a standing height and suffered minor trauma to her right wrist, and then came to our emergency 
department complaining of right wrist pain. During the first pregnancy and 12 months of lactation, she had no discomfort or pain in her hips and low back. The patient had no history of anorexia nervosa, diabetes mellitus, thyroid and parathyroid diseases, rheumatoid arthritis, kidney diseases, or other chronic diseases. She had no medical history of consuming alcohol, smoking, or using drugs. She had no family history of osteoporosis or pathological fracture. She discontinued taking calcium and vitamin during pregnancy. She was $163 \mathrm{~cm}$ in height and weighed $62 \mathrm{~kg}$ (body mass index $23.3 \mathrm{~kg} / \mathrm{m}^{2}$ ). Swelling and deformity of the right wrist were found and the range of motion was restricted. Physical examination showed no obvious abnormality, except for lumbar tenderness. For the safety of the fetus, the patient underwent an emergency MRI examination immediately, which showed Barton fracture in the right wrist (Figure 1). Although the indications for fracture surgery were clear, temporarily closed reduction and plaster external fixation were performed, due to the considering that the patient was about to give birth. At 38 weeks of gestation, she gave birth to a healthy boy and began breastfeeding after delivery. Three days after delivery, the patient was admitted to the orthopedic ward for surgery. The patient underwent imaging examinations (Figure 2) and laboratory tests (Table 1). X-ray examination and CT scan showed the classification and characteristics of the fracture. Laboratory tests showed the levels of serum calcium (Ca), osteocalcin, albumin (ALB), hemoglobin (HGB) and 25-hydroxyvitamin D3 (25-(OH)Vit D3) were decreased, while alkaline phosphatase (ALP) levels were elevated. In order to make a definite diagnosis, bone mineral density (BMD) was measured with dual-energy X-ray absorptiometry (DEXA, HOLOGIC ${ }^{\circledR}$ Discovery-A), which showed the BMD of the lumbar $(\mathrm{L} 1-\mathrm{L} 4)$ as $0.714 \mathrm{~g} / \mathrm{cm}^{2}(\mathrm{Z}$-score $=-2.9)$ and total hip as $0.717 \mathrm{~g} / \mathrm{cm}^{2}(Z$-score $=-1.7)$ (Table 2$)$. The patient was diagnosed as PLO. Considering pain in her low back and the fact that patients with PLO are often associated with vertebral fractures, ${ }^{1,3,5}$ MRI examination was performed and no fractures were found (Figure 1). The patient underwent open reduction and internal fixation (Figure 2) and treated with weaning and supplementation of calcium carbonate (1200 mg/day) and vitamin D (1200 IU/day). The lifestyle of vigorous activities, high protein and high calcium diet, and more sunshine exposure was suggested. The fracture healed 3 months later and the wrist joint function recovered well. Wrist function was evaluated using wrist ranges of motion (ROMs), Disabilities of Arm, Shoulder and Hand (DASH) scores, and GartlandWerley (G-W) scores. The ROMs of the wrist joint were as follows: flexion: $70^{\circ}$,extension: $60^{\circ}$,pronation: $85^{\circ}$,supination: $85^{\circ}$ (Figure 3). The DASH scores were 1.67 , and the G-W scores were 1. During the 1-year follow-up period, the results of laboratory tests and DEXA gradually returned to normal (Table 2).

\section{Discussion}

Pregnancy and lactation-associated osteoporosis (PLO) firstly reported in 1955 is a rare disease, ${ }^{7}$ whose incidence is about 0.4 per 100,000 women. $^{8}$ The incidence of PLO

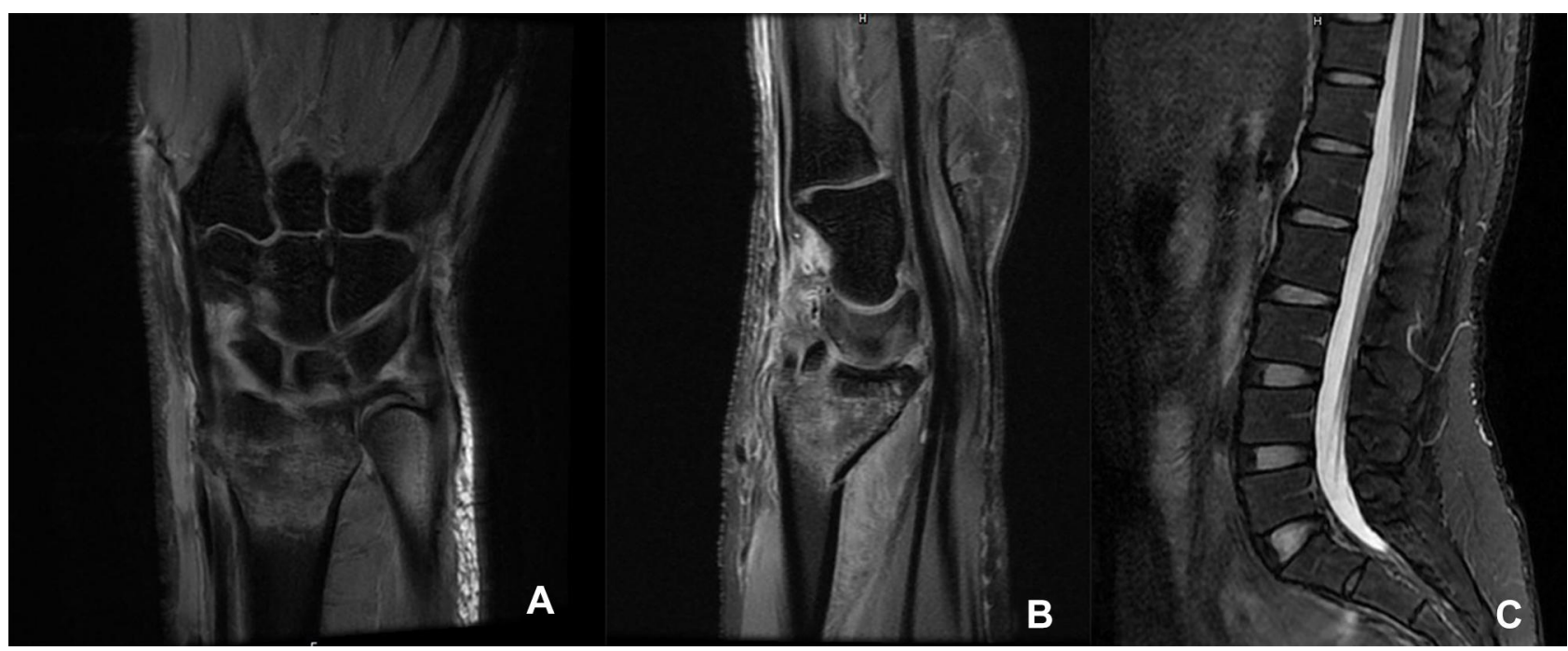

Figure I MRI T2 images (A and B) of the right wrist showed Barton fracture with marrow edema. MRI T2 images (C) showed no fractures in lumbar vertebrae. 


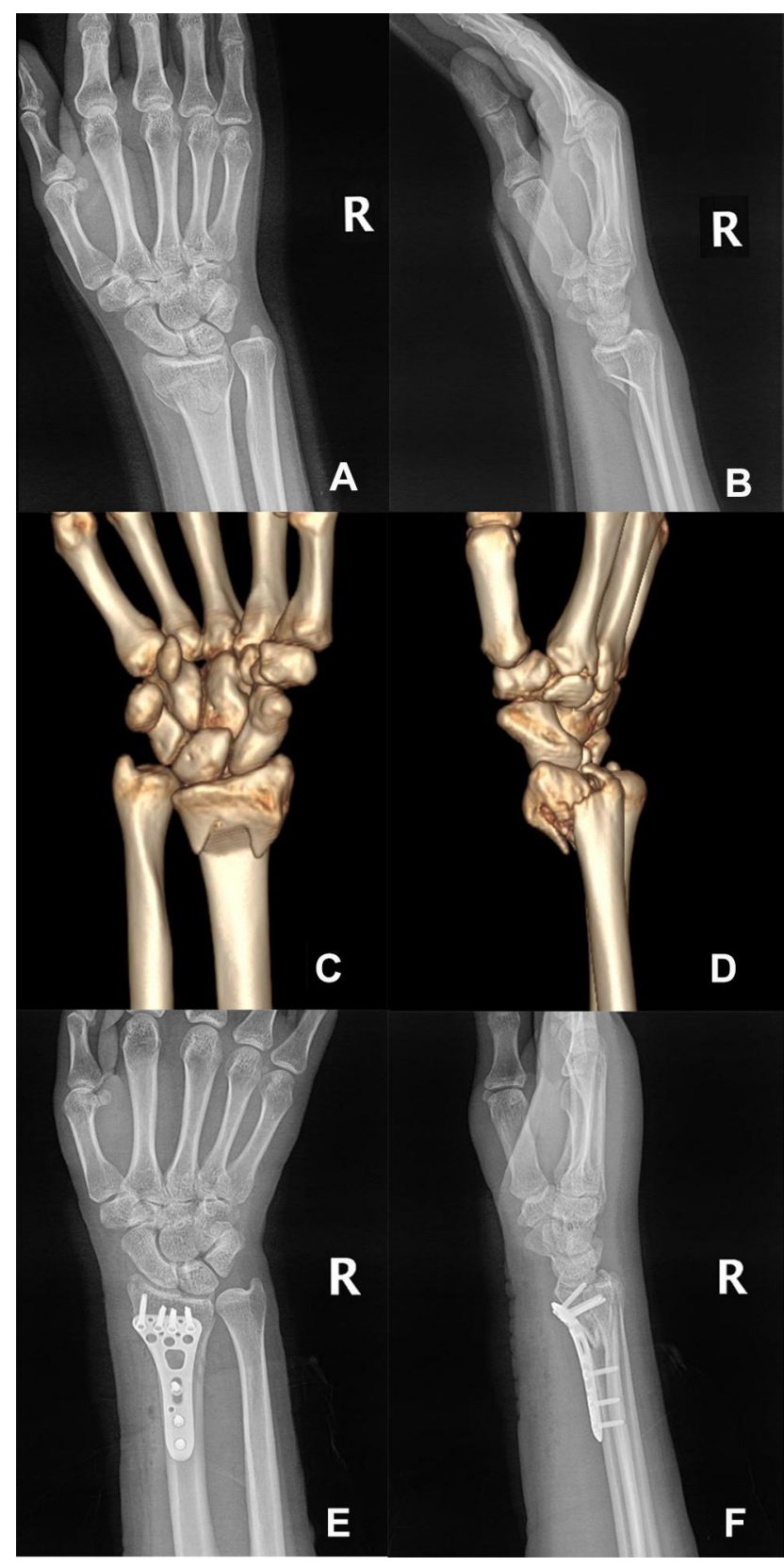

Figure 2 Preoperative $X$-ray films ( $\mathbf{A}$ and $\mathbf{B}$ ) and three-dimensional reconstructive CT images (C and $\mathbf{D}$ ) of right wrist. Postoperative $X$-ray films of right wrist (E and $\mathbf{F}$ ).

should be higher considering the missed diagnosis and the failure of patients to seek medical treatment in time. So far, the etiology, pathogenesis, diagnosis and treatment of PLO remain controversial. ${ }^{1}$

A change in calcium metabolism may contribute to osteoporosis during pregnancy and lactation. ${ }^{9,10}$ To ensure the fetus's calcium requirements, the mother needs more calcium during pregnancy and lactation. ${ }^{10}$ In addition to meeting their own needs, pregnant women must provide about $300-500 \mathrm{mg}$ of calcium daily to the fetus during the final 6 weeks before delivery. ${ }^{11}$ Nearly doubling intestinal calcium absorption largely satisfies fetal calcium demands during pregnancy, although the mechanism and factors of enhancing intestinal absorption are still uncertain. ${ }^{11,12}$ In contrast, this need is met by increased calcium resorption from bone during lactation, which is mediated by parathyroid hormone-related protein (PTHrP). PTHrP is absent in the non-pregnant state and mostly released from the placenta and breasts from the first trimester of pregnancy until delivery. ${ }^{13,14}$ PTHrP levels drop sharply after delivery unless breastfeeding is initiated. ${ }^{14}$ The structure of the first 34 amino acids of PTHrP is similar to that of PTH, which can bind to PTH/PTHrP receptor and promote bone resorption. ${ }^{9}$ High estradiol level during pregnancy significantly inhibited the effect of PTHrP. ${ }^{9}$ When estradiol levels decrease during lactation, PTHrP plays a key role in bone resorption. ${ }^{12,14}$ The PTHrP levels are normalized and the bone density is restored post weaning. ${ }^{15}$ If the calcium demand cannot be met through intestinal calcium absorption during pregnancy and lactation, calcium will be mobilized from the maternal bone through osteoclast activity or osteocytic osteolysis mechanism, ${ }^{12,16}$ which will lead to a decrease in maternal bone mass. In our case, the serum calcium and 25hydroxyvitamin D3 levels of the patient were lower than normal, but gradually increased to the normal range with the improvement of BMD. Unfortunately, PTHrP levels were not checked in our case. It seems that calcium metabolism imbalance contributes to the cause of PLO. However, it was found that calcium and vitamin D intake was not associated with BMD changes in a controlled cohort study. ${ }^{17}$ In addition, this hypothesis cannot explain why some people exhibit PLO while others do not, although both in the same state of lower calcium and vitamin D. ${ }^{18}$ It seems that there are other factors that can cause bone loss.

Maybe hereditary factors also play a role that we do not know yet. Dunne et al reported that fracture prevalence in mothers of patients with PLO (16/29) was higher compared to the control group (7/29), particularly the majority of these mothers had fractured before the age of 45 years (11/16) compared to the control group (2/7). ${ }^{19}$ Peris et al reported that osteoporosis was present in $53 \%$ of the relatives of patients with PLO compared with $15 \%$ in the control. ${ }^{20}$ Although our patient had no family history of osteoporosis, we should not ignore the possible influence of hereditary factors. 
Table I Laboratory Tests Related to Bone and Mineral Metabolism

\begin{tabular}{|l|l|l|l|l|l|l|}
\hline Measurements & $\mathbf{0}$ & $\mathbf{3 m}$ & $\mathbf{6 m}$ & $\mathbf{9 m}$ & $\mathbf{1 2 m}$ & Reference \\
\hline Ca $(\mathrm{mmol} / \mathrm{L})$ & 2.01 & 2.21 & 2.25 & 2.31 & 2.30 & $2.1 \mathrm{I}-2.52$ \\
$\mathrm{P}(\mathrm{mmol} / \mathrm{L})$ & 0.97 & 1.23 & 1.32 & 1.29 & 1.21 & $0.85-1.51$ \\
ALP $(\mathrm{U} / \mathrm{L})$ & 175 & 67 & 45 & 41 & 39 & $35-100$ \\
$25-(\mathrm{OH})$ Vit D3 $(\mathrm{ng} / \mathrm{mL})$ & 9.21 & 13.33 & 14.52 & 15.12 & 15.04 & $20-32$ \\
Osteocalcin $(\mathrm{ng} / \mathrm{mL})$ & 11.67 & 24.55 & 27.43 & 28.45 & 29.11 & $17-43$ (in premenopause) \\
& & & & & & $15-46$ (in postmenopause) \\
PTH (pg/mL) & 57.79 & 73.82 & 43.07 & 34.56 & 35.76 & $11-62$ \\
ALB (g/L) & 29.9 & 42.3 & 43.2 & 42.9 & 42.8 & $40-55$ \\
HGB $(\mathrm{g} / \mathrm{L})$ & 103 & 122 & 126 & 131 & 130 & $115-150$ \\
\hline
\end{tabular}

Abbreviations: Ca, calcium; P, phosphorus, ALP, alkaline phosphatase; PTH, parathyroid hormone; ALB, albumin; HGB, hemoglobin.

Table 2 Changes in the Results of DEXA

\begin{tabular}{|c|c|c|c|c|c|c|c|c|c|c|}
\hline \multirow{2}{*}{$\begin{array}{l}\text { Examination } \\
\text { Sites }\end{array}$} & \multicolumn{2}{|l|}{0} & \multicolumn{2}{|l|}{$3 m$} & \multicolumn{2}{|l|}{$6 m$} & \multicolumn{2}{|l|}{$9 m$} & \multicolumn{2}{|l|}{$12 \mathrm{~m}$} \\
\hline & $\begin{array}{l}\text { BMD } \\
\left(\mathrm{g} / \mathrm{cm}^{2}\right)\end{array}$ & Z-score & $\begin{array}{l}\text { BMD } \\
\left(\mathrm{g} / \mathrm{cm}^{2}\right)\end{array}$ & Z-score & $\begin{array}{l}\text { BMD } \\
\left(\mathrm{g} / \mathrm{cm}^{2}\right)\end{array}$ & Z-score & $\begin{array}{l}\text { BMD } \\
\left(\mathrm{g} / \mathrm{cm}^{2}\right)\end{array}$ & Z-score & $\begin{array}{l}\text { BMD } \\
\left(\mathrm{g} / \mathrm{cm}^{2}\right)\end{array}$ & Z-score \\
\hline LI & 0.682 & -2.7 & 0.791 & -1.7 & 0.811 & -1.5 & 0.883 & -0.9 & 1.030 & 0.4 \\
\hline L2 & 0.667 & -3.1 & 0.836 & -1.6 & 0.894 & -1.1 & 0.960 & -0.5 & 1.074 & 0.5 \\
\hline L3 & 0.755 & -3.0 & 0.850 & -2.0 & 0.925 & -1.3 & 0.997 & -0.7 & 1.141 & 0.6 \\
\hline L4 & 0.742 & -2.8 & 0.812 & -2.1 & 0.937 & -1.0 & 0.918 & -1.2 & 1.056 & 0.0 \\
\hline Total (LI-L4) & 0.714 & -2.9 & 0.823 & -1.9 & 0.895 & -1.3 & 0.939 & -0.8 & 1.078 & 0.3 \\
\hline Hip neck & 0.571 & -2.3 & 0.649 & -1.6 & 0.732 & -0.9 & 0.797 & -0.2 & 0.837 & 0.1 \\
\hline Total hip & 0.717 & -1.7 & 0.833 & -0.8 & 0.86 & -0.6 & 0.887 & -0.3 & 0.971 & 0.3 \\
\hline
\end{tabular}

Abbreviation: L, lumbar.

Mutations in COL1A1 or COL1A2 can be identified in about $90 \%$ of individuals with osteogenesis imperfect, which is the best-known form of monogenic osteoporosis. ${ }^{21}$ Collet et al found variants in COL1A2 and LRP5in a cohort of 123 young or middle-aged adults with idiopathic osteoporosis. ${ }^{22}$ Therefore, gene mutation may also be a potential cause of PLO. Butscheidt et al found three novel mutations in LRP5, COL1A1, and COL1A2 in the gene analysis of seven patients diagnosed with pregnancy-associated osteoporosis. ${ }^{23}$ A Caucasian woman in the seventh month of her first pregnancy underwent DNA analyses and it was revealed two compound heterozygous mutations in LRP5. ${ }^{24}$ With the progress of gene detection technology, it is believed that more discoveries will be made in the future.

In addition to the above three risk factors, other factors such as duration of lactation and the age of first delivery, ${ }^{25}$ lack of physical exercise, ${ }^{1}$ low body weight in childhood and puberty may also lead to PLO. ${ }^{26}$ In our case, the patient was healthy during the first pregnancy and 12 months of lactation, while she was diagnosed as PLO this time. The pathogenesis and etiology of PLO need further study.
At present, the treatment of PLO is still controversial because of the rareness of PLO and reported cases. Most PLO patients receive calcium and vitamin besides weaning. Nordin et al, who firstly reported PLO, treated patients with weaning and supplementation of calcium. ${ }^{7}$ After 8-18 months of weaning, calcium and vitamin D supplementation, Philips et al found that spine BMD increased by $6.21 \%$ in 13 patients. ${ }^{27}$ In our case, the patient achieved satisfactory results through this treatment, which has been confirmed by other studies. ${ }^{5,6,28}$

Bisphosphonate therapy has been proved to be effective in patients with PLO, besides weaning and supplementation of calcium and vitamin D. ${ }^{19,28}$ O'Sullivan et al found that BMD increased by $17 \%$ in 11 cases of PLO patients treated with bisphosphonate therapy. ${ }^{28}$ However, bisphosphonates accumulated in the bones can cross the placenta to the fetus during a subsequent pregnancy. ${ }^{29,30}$ Twenty percent of congenital malformations were reported in ten cases of women treated with bisphosphonate during pregnancy. ${ }^{31}$ Bisphosphonates should be used cautiously in women in pregnancy or in a plausible future pregnancy. Therefore, there are other options for PLO patients expecting another 


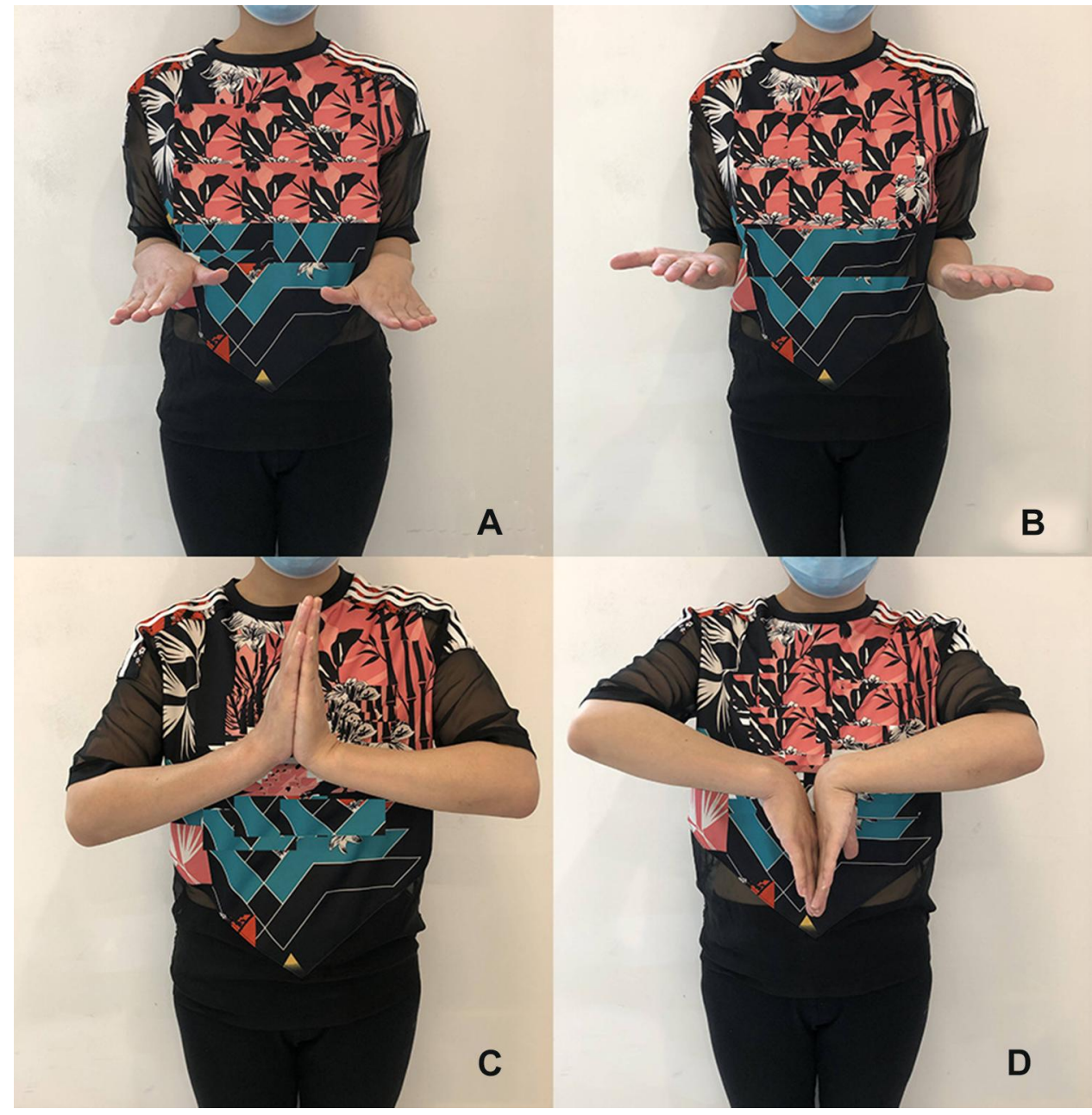

Figure 3 Follow-up after 3 months of surgery of the patient. The pronation and supination of forearm (A and $\mathbf{B})$. The flexion and extension functions of wrist (C and $\mathbf{D})$.

pregnancy, such as teriparatide, the human recombinant parathyroid hormone (1-34). ${ }^{32-34}$ Teriparatide has been assigned to pregnancy category $\mathrm{C}$ by the FDA. ${ }^{35}$ The results of teriparatide treatment in three cases of PLO were satisfactory. ${ }^{32}$ After 13 months of teriparatide treatment, BMD was increased at the lumbar spine and hips in a woman suffering from severe PLO with 6 vertebral fragility fractures. ${ }^{33}$

BMD at the lumbar spine, femur neck and the total hip improved by $16.7 \%, 3.0 \%$ and $10.2 \%$ in a 25 -year-old Caucasian woman after 6 months of teriparatide treatment. $^{34}$

The prognosis of PLO is good, although it causes great pain and inconvenience. ${ }^{36}$ Gehlen et al found that 20 patients of PLO improved within the first 2 years and it took them 3.3 years on average time to return to employment. ${ }^{36}$ In our case, the results of laboratory tests and DEXA gradually returned to normal during the 1-year follow-up period.
The radiological imaging is helpful in detecting fractures and osteoporosis. BMD assessed by DEXA decreased significantly at the lumbar spine and hip during pregnancy. ${ }^{17,27}$ Decreases in bone mass at the lumbar spine and hip are also associated with the amount of breast milk produced and the duration of lactation. ${ }^{28,29}$ However, there is still no definite conclusion on the change of BMD at the distal forearm. Some studies have confirmed the decrease of $\mathrm{BMD},{ }^{17,37}$ while others have reached the opposite conclusion. ${ }^{38}$ Correspondingly, there are few reports of distal radius fractures in PLO patients compared with vertebral compression fractures or hip fractures. ${ }^{1,5,6}$ Distal radius fractures are common fractures, accounting for about one-sixth of the total fractures. The incidence of Barton fracture is about $1 / 10$ of distal radius fractures, which was first described by John Rhea Barton in $1838 .^{39}$ This fracture entails either dorsal or volar fracturedislocation of the wrist, which is often distinguished from 
the Colles fractures and Smith fractures. ${ }^{40}$ In our case, the emergency MRI results showed that the prognosis of conservative treatment was poor and surgery was needed. Given that the patient was about to give birth, we carried out simple manipulative closed reduction and plaster external fixation to reduce the swelling and pain of the right wrist. Considering pain in her low back and the fact that patients with PLO are often associated with vertebral fractures, ${ }^{1,3,5}$ MRI examination was performed. Fortunately, no vertebral fractures were found. The patient underwent open reduction and internal fixation after delivery. The patient was instructed to carry out postoperative rehabilitation training for the right wrist. The fracture healed 3 months later and the wrist joint function recovered well.

\section{Conclusion}

Clinicians should be alert to the possibility of PLO to avoid missed diagnosis, especially for patients suffering from fractures caused by minor trauma or complaining of low back/hip pain during pregnancy and lactation. Accurate diagnosis and individualized treatment are of great significance for relieving pain and functional recovery of patients.

\section{Abbreviations}

PLO, pregnancy and lactation-associated osteoporosis; BMD, bone mineral density; DEXA, dual-energy X-ray absorptiometry.

\section{Data Sharing Statement}

Please contact the author for data requests.

\section{Ethics Approval and Consent to Participate}

The study was approved by the ethics committee of Beijing Friendship Hospital. The patient provided written informed consent to have the case details and any accompanying images published. This study was conducted in accordance with the latest version of the Declaration of Helsinki. This subject was ensured anonymity, which was maintained by using subject-specific numeric code on the record, including registration card.

\section{Author Contributions}

All authors contributed to data analysis, drafting or revising the article, have agreed on the journal to which the article will be submitted, gave final approval of the version to be published, and agree to be accountable for all aspects of the work.

\section{Funding}

There is no funding to report.

\section{Disclosure}

The authors declare that they have no competing interests.

\section{References}

1. Winter EM, Ireland A, Butterfield NC, et al. Pregnancy and lactation, a challenge for the skeleton. Endocr Connect. 2020;9(6):R143-R157. doi:10.1530/EC-20-0055

2. Evenson KR, Wen F. Prevalence and correlates of objectively measured physical activity and sedentary behavior among US pregnant women. Prev Med. 2011;53(1-2):39-43. doi:10.1016/j.ypmed.2011. 04.014

3. Kuroda T, Nagai T, Ishikawa K, et al. Clinical features and diagnosis of lumbar fractures caused by pregnancy- and lactation-associated osteoporosis. Clin Calcium. 2019;29(1):46-50.

4. Gehlen M, Lazarescu AD, Hinz C, et al. [Pregnancy and lactation-associated osteoporosis]. Z Rheumatol. 2017;76(3):27 4-278. doi:10.1007/s00393-016-0259-Z

5. Jia P, Wang R, Yuan J, et al. A case of pregnancy and lactation-associated osteoporosis and a review of the literature. Arch Osteoporos. 2020;15(1):94. doi:10.1007/s11657-020-00768-7

6. Jun Jie Z, Ai G, Baojun W, et al. Intertrochanteric fracture in pregnancy- and lactation-associated osteoporosis. J Int Med Res. 2019;300060519858013.

7. Nordin BE, Roper A. Post-pregnancy osteoporosis. A syndrome P Lancet. 1955;268(6861):431-434. doi:10.1016/S0140-6736(55)90214-2

8. Hellmeyer L, Hadji P, Ziller V, et al. Osteoporose in der Schwangerschaft. Geburtshilfe Frauenheilkd. 2004;64:38-45.

9. Kovacs CS, Ralston SH. Presentation and management of osteoporosis presenting in association with pregnancy or lactation. Osteoporos Int. 2015;26(9):2223-2241. doi:10.1007/s00198-015-3149-3

10. Kovacs CS, Kronenberg HM. Maternal-fetal calcium and bone metabolism during pregnancy, puerperium, and lactation. Endocr Rev. 1997;18(6):832-872.

11. Kovacs CS. Bone development and mineral homeostasis in the fetus and neonate: roles of the calciotropic and phosphotropic hormones. Physiol Rev. 2014;94(4):1143-1218.

12. Kovacs CS. Maternal mineral and bone metabolism during pregnancy, lactation, and post-weaning recovery. Physiol Rev. 2016;96 (2):449-547.

13. Winter EM, Appelman-Dijkstra NM. Parathyroid hormone-related protein-induced hypercalcemia of pregnancy successfully reversed by a dopamine agonist. J Clin Endocrinol Metab. 2017;102 (12):4417-4420. doi:10.1210/jc.2017-01617

14. Ardawi MS, Nasrat HA, BA'Aqueel HS. Calcium-regulating hormones and parathyroid hormone-related peptide in normal human pregnancy and postpartum: a longitudinal study. Eur J Endocrinol. 1997;137(4):402-409.

15. Kim HW, Song JW, Kwon A, et al. Percutaneous vertebroplasty for pregnancy-associated osteoporotic vertebral compression fractures. J Korean Neurosurg Soc. 2010;47(5):399-402. doi:10.3340/jkns.20 10.47.5.399

16. Wein MN. Parathyroid hormone signaling in osteocytes. JBMR Plus. 2018;2(1):22-30. doi:10.1002/jbm4.10021 
17. Moller UK, Við Streym S, Mosekilde L, et al. Changes in bone mineral density and body composition during pregnancy and postpartum. A controlled cohort study. Osteoporos Int. 2012;23(4): 1213-1223. doi:10.1007/s00198-011-1654-6

18. Miyamoto T, Miyakoshi K, Sato Y, et al. Changes in bone metabolic profile associated with pregnancy or lactation. Sci Rep. 2019;9(1):1-13.

19. Dunne F, Walters B, Marshall T, et al. Pregnancy associated osteoporosis. Clin Endocrinol (Oxf). 1993;39(4):487-490. doi:10.11 11/j.1365-2265.1993.tb02398.x

20. Peris P, Guanabens N, Monegal A, et al. Pregnancy associated osteoporosis: the familial effect. Clin Exp Rheumatol. 2002;20(5):69 7-700.

21. Basel D, Steiner RD. Osteogenesis imperfecta: recent findings shed new light on this once well-understood condition. Genet Med. 2009;11(6):375-385. doi:10.1097/GIM.0b013e3181a1ff7b

22. Collet C, Ostertag A, Ricquebourg M, et al. Primary osteoporosis in young adults: genetic basis and identification of novel variants in causal genes. JBMR Plus. 2018;2(1):12-21. doi:10.1002/jbm4.10020

23. Butscheidt S, Delsmann A, Rolvien T, et al. Mutational analysis uncovers monogenic bone disorders in women with pregnancy-associated osteoporosis: three novel mutations in LRP5, COL1A1, and COL1A2. Osteoporos Int. 2018;29(7):1643-1651. doi:10.1007/s00198-018-4499-4

24. Campos-Obando N, Oei L, Hoefsloot LH, et al. Osteoporotic vertebral fractures during pregnancy: be aware of a potential underlying genetic cause. J Clin Endocrinol Metab. 2014;99(4):1107-1111. doi: $10.1210 /$ jc. $2013-3238$

25. Bolzetta F, Veronese N, De Rui M, et al. Duration of breastfeeding as a risk factor for vertebral fractures. Bone. 2014;68:41-45. doi:10.1016/j.bone.2014.08.001

26. Hadji P, Boekhoff J, Hahn M, et al. Pregnancy-associated osteoporosis: a case-control study. Osteoporos Int. 2017;28(4):1393-1399. doi:10.1007/s00198-016-3897-8

27. Phillips AJ, Ostlere SJ, Smith R. Pregnancy-associated osteoporosis: does the skeleton recover? Osteoporos Int. 2000;11(5):449-454. doi:10.1007/s001980070113

28. O'Sullivan SM, Grey AB, Singh R, et al. Bisphosphonates in pregnancy and lactation-associated osteoporosis. Osteoporos Int. 2006;17 (7):1008-1012. doi:10.1007/s00198-006-0112-3
29. Hassen-Zrour S, Korbâa W, Béjia I, et al. Maternal and fetal outcome after long-term bisphosphonate exposure before conception. Osteoporos Int. 2010;21(4):709-710. doi:10.1007/s00198-009-0983-1

30. Patlas N, Golomb G, Yaffe P, et al. Transplacental effects of bisphosphonates on fetal skeletal ossification and mineralization in rats. Teratology. 1999;60(2):68-73.

31. Losada I, Sartori L, Di Gianantonio E, et al. Bisphosphonates in patients with autoimmune rheumatic diseases: can they be used in women of childbearing age? Autoimmun Rev. 2010;9(8):547-552. doi:10.1016/j.autrev.2010.03.002

32. Choe EY, Song JE, Park KH, et al. Effect of teriparatide on pregnancy and lactation-associated osteoporosis with multiple vertebral fractures. J Bone Miner Metab. 2012;30(5):596-601. doi:10.1007/ s00774-011-0334-0

33. Lampropoulou-Adamidou K, Trovas G, Stathopoulos I, et al. Case report: teriparatide treatment in a case of severe pregnancy -and lactation- associated osteoporosis. Hormones (Athens). 2012;11 (4):495-500. doi:10.14310/horm.2002.1383

34. Coskun BI, Sarpel T, Guzel R. Short-term treatment experience with teriparatide in pregnancy- and lactation-associated osteoporosis. J Obstet Gynaecol. 2014;34(8):736. doi:10.3109/01443615.2014.92 0800

35. Quattrocchi E, Kourlas H. Teriparatide: a review. Clin Ther. 2004;26 (6):841-854. doi:10.1016/S0149-2918(04)90128-2

36. Gehlen M, Lazarescu AD, Hinz C, et al. Long-term outcome of patients with pregnancy and lactation-associated osteoporosis (PLO) with a particular focus on quality of life. Clin Rheumatol. 2019;38 (12):3575-3583. doi:10.1007/s10067-019-04758-0

37. More C, Bettembuk P, Bhattoa HP, et al. The effects of pregnancy and lactation on bone mineral density. Osteoporos Int. 2001;12 (9):732-737. doi:10.1007/s001980170048

38. Ulrich U, Miller PB, Eyre DR, et al. Bone remodeling and bone mineral density during pregnancy. Arch Gynecol Obstet. 2003;268 (4):309-316. doi:10.1007/s00404-002-0410-8

39. Ellis J. Smith's and Barton's fractures: a method of treatment. J Bone Joint Surg Br. 1965;47(4):724-727. doi:10.1302/0301-620X.47B4. 724

40. Mehara AK, Rastogi S, Bhan S, et al. Classification and treatment of volar Barton fractures. Injury. 1993;24(1):55-59. doi:10.1016/00201383(93)90085-K
International Journal of General Medicine

\section{Publish your work in this journal}

The International Journal of General Medicine is an international, peer-reviewed open-access journal that focuses on general and internal medicine, pathogenesis, epidemiology, diagnosis, monitoring and treatment protocols. The journal is characterized by the rapid reporting of reviews, original research and clinical studies across all disease areas. The manuscript management system is completely online and includes a very quick and fair peer-review system, which is all easy to use. Visit http://www.dovepress.com/ testimonials.php to read real quotes from published authors. 